\title{
Dietary sugars intake and micronutrient adequacy: a systematic review of the evidence
}

\author{
Sigrid A. Gibson \\ Sig-Nurture Ltd, 11 Woodway, Guildford, Surrey, GU1 2TF, UK
}

\begin{abstract}
Guidelines for sugars intake range from a population mean of less than $10 \%$ energy from free sugars, to a maximum for individuals of $25 \%$ energy from added sugars. The aim of the present review was to examine the evidence for micronutrient dilution by sugars and evaluate its nutritional significance. From a web-based search of MEDLINE and hand search of linked papers, forty-eight relevant publications were identified on sugars (total sugars, non-milk extrinsic sugars, or added sugars) or sugar-containing drinks. These included five reports from expert committees, six reviews, thirty-three observational studies and four small-scale interventions. There was inconsistency between studies as to the relationship between sugars intake (however expressed) and micronutrients. The statistical patterns varied between nutrients and population groups. Curvilinear associations were found in some analyses, with lower nutrient intakes at both extremes of sugar intake; however, factors such as dieting and under-reporting may confound the associations observed. Some studies found statistically significant inverse associations but these were weak, with sugars explaining less than $5 \%$ of the variance. Mean intakes of most micronutrients were above the RDA or reference nutrient intake except among very high consumers of sugars. The available evidence does not allow for firm conclusions on an optimal level of added sugars intake for micronutrient adequacy and the trends that exist may have little biological significance except for a few nutrients (for example, Fe). It is established that energy intake is the prime predictor of micronutrient adequacy. A better understanding of valid approaches to energy adjustment, misreporting and the assessment of micronutrient adequacy is crucial to further progress in this area.
\end{abstract}

\section{Sugars intake: Micronutrient adequacy}

\section{Introduction}

The aim of the present review was to collate and critically examine the evidence that dietary sugars compromise micronutrient intakes, to evaluate the nutritional significance and if possible to assess the range of sugars intake associated with micronutrient adequacy.

\section{Methods}

Relevant articles published between 1980 and 2006 were identified by searching the MEDLINE database (National Library of Medicine, Bethesda, MD, USA). Search terms included sugar(s) (total sugars, added sugars or non-milk extrinsic sugars (NMES)), sucrose, and soft drinks, sweetened beverages, (with) nutrient intake, micronutrient, nutrient dilution, or empty calorie. This web-based search was supplemented by a hand-search of linked references and recent articles in specialist journals. Studies were included if they examined the association between micronutrient intakes and consumption of sugars or soft drinks, whether they were surveys, reports, reviews or interventions. Simple temporal associations (trends in sugars intake) were not included. Citations and abstracts were imported into a bibliographic database (EndNote, version 8; Thomson ResearchSoft, Carlsbad, CA, USA) ${ }^{1}$ and papers were obtained from journals, libraries or authors. Articles were classified according to their study design, dietary methodology, definition of sugars, subject age and country of origin. We noted reported associations with micronutrients, their nutritional importance (in comparison with dietary reference values) and the range of sugars intake associated with adequacy.

\footnotetext{
Abbreviations: CSFII, Continuing Survey of Food Intakes by Individuals; \%EAS, percentage energy from added sugars; NHANES III,
} third National Health and Nutrition Examination Survey; NMES, non-milk extrinsic sugars.

Corresponding author: Sigrid Gibson, fax +44 1483 838018, email sigrid@ sig-nurture.com 


\section{Results: overview of studies and methods}

Forty-seven relevant papers and reports on the association between sugars and micronutrient intakes were identified. Four of the studies were interventions, while thirty-three were observational. There were also five major reports and six reviews.

Studies defined sugars in various ways (total sugars, NMES, added sugars, sucrose or 'sugar') and most express sugars intake as a percentage of energy intake. Some adjustment for energy is essential in seeking to quantify the independent impact of nutrients on health outcomes but there are various approaches with different strengths and weaknesses $^{2}$. Forshee et al. have criticised the use of percentage energy from sugars as inherently biased because its application presupposes the displacement it seeks to prove $^{3}$. This methodological debate is beyond the remit of the present review but the reader should be aware that estimates of the extent of dilution by sugars are a consequence of the methodology used.

The intervention studies are shown in Table $1^{4-7}$, and the observational studies in Tables $2-4^{3,8-39}$. The major reports $^{40-44}$ are discussed in the 'Recommendations from expert committees' section and the reviews ${ }^{45-50}$ in the 'Reviews' section.

\section{Recommendations from expert committees}

In the UK, the 1989 Department of Health Committee on Medical Aspects of Food Policy (COMA) report on dietary sugars and human disease ${ }^{40}$ considered the issue of micronutrient dilution by NMES from the limited studies available at the time. No quantitative recommendations were given, but the report concluded (1) 'that sugars intake is a weaker predictor of absolute micronutrient intakes than total energy consumption' and (2) 'that at any level of energy intake, a higher sugars intake is associated with lower micronutrient intakes'. This observation was clearest at the lowest energy intakes. Since 1990, a number of expert committees worldwide have issued guidance on recommended levels of sugars in the diet, although it is not always clear whether this is related to micronutrient dilution or other rationales. Recently, the WHO/FAO in their report on diet, nutrition and the prevention of chronic diseases reiterated their previous recommendation of less than $10 \%$ energy from 'free' sugars, with the assertion that 'higher intakes of free sugars threaten the nutrient quality of diets', although no evidence was presented to support this proposed limit ${ }^{41}$.

The report of the (UK) panel on dietary reference values set a target of $10 \%$ of total energy from NMES but this was on the grounds of caries prevention ${ }^{42}$. The definition of NMES was intended to comprise sugars that are neither derived from milk nor incorporated within the cellular structure of food; in practice the NMES content represents added sugars, plus sugars in fruit juice and $50 \%$ of the sugars in processed and dried fruit. The UK report commented at the time that data in support of any specific quantified targets for NMES were scanty.

In the USA, non-quantitative guidance on sugars intake was included in Dietary Guidelines for Americans.

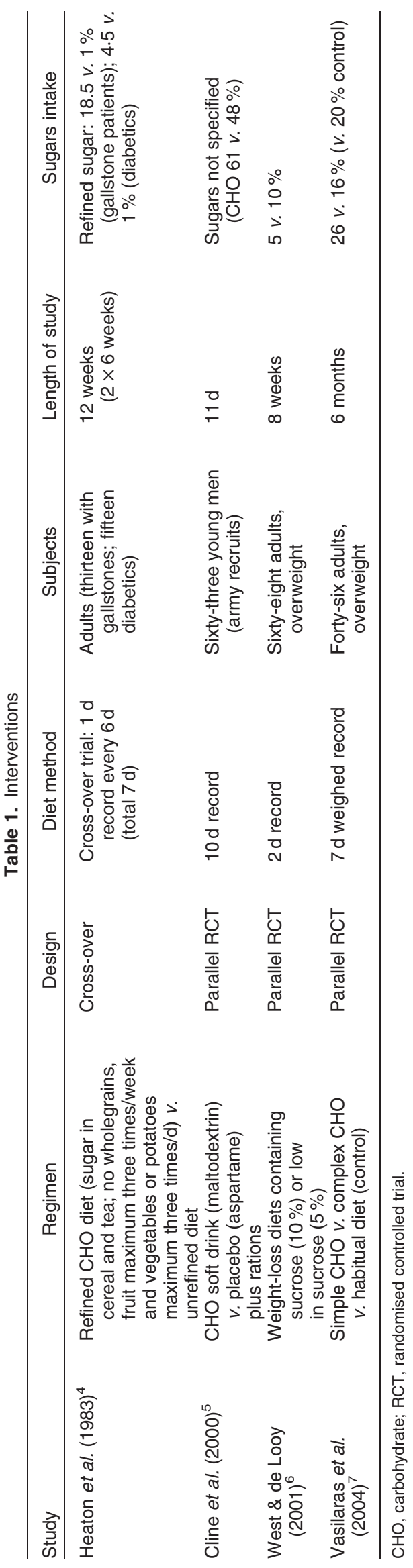


Table 2. Observational studies of added sugars

\begin{tabular}{|c|c|c|c|}
\hline Study & Country & Diet method & Age group \\
\hline $\begin{array}{l}\text { Charlton et al. } \\
(1998)^{8}\end{array}$ & $\begin{array}{l}\text { South } \\
\text { Africa }\end{array}$ & FFQ & Older adults \\
\hline $\begin{array}{l}\text { Baghurst et al. } \\
(1992)^{9}\end{array}$ & Australia & 24RCL & Adults \\
\hline $\begin{array}{l}\text { Bowman } \\
\left(^{(1999)^{10}}\right.\end{array}$ & USA & $24 \mathrm{RCL}$ & All \\
\hline $\begin{array}{l}\text { Britten et al. } \\
(2000)^{11}\end{array}$ & USA & $24 \mathrm{RCL}$ & All \\
\hline $\begin{array}{l}\text { Forshee \& } \\
\text { Storey } \\
(2001)^{12}\end{array}$ & USA & $24 \mathrm{RCL}$ & $\begin{array}{c}\text { Children, } \\
\text { youth }\end{array}$ \\
\hline $\begin{array}{c}\text { Forshee \& } \\
\text { Storey } \\
(2004)^{3}\end{array}$ & USA & $24 \mathrm{RCL}$ & $\begin{array}{c}\text { Children, } \\
\text { youth }\end{array}$ \\
\hline $\begin{array}{l}\text { Charlton et al. } \\
(2005)^{13}\end{array}$ & $\begin{array}{l}\text { South } \\
\quad \text { Africa }\end{array}$ & $24 \mathrm{RCL}$ & Older adults \\
\hline $\begin{array}{l}\text { Kranz et al. } \\
(2005)^{14}\end{array}$ & USA & $2 \times 24 R C L$ & $\begin{array}{l}\text { Young } \\
\text { children }\end{array}$ \\
\hline $\begin{array}{l}\text { Lewis et al. } \\
\qquad(1992)^{15}\end{array}$ & USA & 3Ddiary & All \\
\hline $\begin{array}{l}\text { Rugg-Gunn } \\
\text { et al. (1991) }\end{array}$ & UK & 3WDR & Children \\
\hline $\begin{array}{l}\text { Alexy et al. } \\
(2002)^{17}\end{array}$ & Germany & 3WDR & $\begin{array}{c}\text { Children, } \\
\text { youth }\end{array}$ \\
\hline $\begin{array}{l}\text { Alexy et al. } \\
(2003)^{18}\end{array}$ & Germany & $3 W D R$ & $\begin{array}{c}\text { Children, } \\
\text { youth }\end{array}$ \\
\hline $\begin{array}{l}\text { Alexy et al. } \\
(2003)^{19}\end{array}$ & Germany & $3 W D R$ & $\begin{array}{c}\text { Children, } \\
\text { youth }\end{array}$ \\
\hline $\begin{array}{l}\text { Øverby et al. } \\
\qquad(2004)^{20}\end{array}$ & Norway & 4Ddiary & Children \\
\hline $\begin{array}{l}\text { Flynn et al. } \\
\qquad(1996)^{21}\end{array}$ & Ireland & 7dhistory & Adults \\
\hline Gibson $(1997)^{22}$ & UK & 7WDR & Adults \\
\hline
\end{tabular}

Inverse associations with micronutrient density of thiamin, vitamin $\mathrm{E}, \mathrm{Fe}, \mathrm{Zn}, \mathrm{Cu}, \mathrm{Mg}$ (among men) and all nutrients except vitamin $\mathrm{D}$ and vitamin $\mathrm{E}$ among women. No association with energy intake

Weak negative trends found for $\mathrm{B}_{6}$, folate, carotene, $\mathrm{Mg}$, vitamin $\mathrm{C}$ (women only) but not for $\mathrm{Fe}$, thiamin, riboflavin, niacin in women, or vitamin $\mathrm{C}$ in men. Positive association with $\mathrm{Ca}$ among men. Intakes above RDA across range 4 to $16 \%$ sugars intake

Highest tertile ( $>18 \%$ energy; mean $26 \%$ ) had lower intakes of vitamins $A, C, B_{12}$, folate, and o minerals $\mathrm{Ca}, \mathrm{P}, \mathrm{Mg}$ and $\mathrm{Fe}$ and did not meet $\mathrm{RDA}$ for vitamins $\mathrm{E}$ and $\mathrm{B}_{6}$, and $\mathrm{Ca}, \mathrm{Mg}$ and $\mathrm{Zn}$

Examined diet quality (not nutrient intakes). High sugar consumers ate less fruit but the association with diet quality depended on energy intake

Both positive and negative associations were small and varied with age group. Children who consume more added sugars are predicted to consume more vitamin C, Fe and folates and less dairy. Adolescents who consume more added sugars are predicted to consume more vitamin $\mathrm{C}$ and $\mathrm{Fe}$ and less fruit

Using an alternative statistical approach (energy partitioning) the association of energy from added sugars with micronutrient intake was inconsistent and small compared with energy from other sources

Among women only, highest tertile sugar consumers (mean $18 \%$ added sugars) had lower micronutrient intakes (and lower energy intake), and also suboptimal erythrocyte folate and plasma ascorbic acid status

Increasing added sugar consumption was paralleled by decreasing nutrient and food group intakes and increasing proportions of children with intakes below the DRI. Ca intake was insufficient in large proportions of children consuming $16 \%$ or more from added sugar

Lower intakes of eleven nutrients in high quartile consumers (16-25\%) v. moderate consumers (6$15 \%)$

Consumption of large amounts of added sugars $(19 \mathrm{v} .10 \%)$ was associated with marginally lower intakes of several nutrients. Associations were not significant except for vitamin $D$

No significant nutrient dilution by added sugars. The positive effect of fortification on nutrient densities was greater than the negative effect of added sugars

A median intake of $12 \%$ added sugars was associated with highest dietary quality as measured by nutrient intake score

A slight, but statistically significant, nutrient-dilution effect of added sugars and a significant reduction in intake of important nutrient-bearing food groups. No clear indicator on grounds of micronutrient dilution for a quantitative limit of added sugars

Negative association between the intake of added sugar and intakes of micronutrients (except vitamins $\mathrm{C}$ and $\mathrm{E}$ ) and fruit and vegetables. Nutritional consequences of increasing added sugar in the diet differ strongly from one nutrient to another and across age groups

Diets higher in sugar are not necessarily more dilute in micronutrients. Eighty-three women classified by fat energy. Lowest quartile fat group had highest sugar intake (mean $12.4 \%$ added sugar) and higher intakes of fibre, vitamin $\mathrm{C}$ and folate compared with high fat group (6\% sugar) but lower vitamin $\mathrm{A}$

Many nutrients showed a non-linear relationship with sugars energy (added, NMES, or total). Intakes fell in Q4 and Q5 (> 15\% added sugars or > about 17\% NMES) but were above RNI (except for Fe and folate among women)
Range of sugars associated with highest micronutrient intakes*

None given

$4-16 \%$

$<18 \%$

None given

None given

None given

'10\% appropriate

in this population

$<16 \%$

$6-15 \%$

None given

None given

$6-12 \%$

'No grounds'

$<13 \%$

None given

$<15 \%$ added

sugars

$24 \mathrm{RCL}=24 \mathrm{~h}$ recall; $\mathrm{DRI}=$ dietary reference intake; $3 \mathrm{Ddiary}=3 \mathrm{~d}$ dietary diary; $3 \mathrm{WDR}=3 \mathrm{~d}$ weighed dietary record; $4 \mathrm{Ddiary}=4 \mathrm{~d}$ dietary diary; $7 \mathrm{dhistory}=7 \mathrm{~d}$ food history; $7 \mathrm{WDR}=7 \mathrm{~d}$ weighed dietary record; NMES = non-milk extrinsic sugars; $Q 4=$ fourth quintile; $Q 5=$ fifth quintile; $R N I$ = reference nutrient intake.

${ }^{*}$ Ranges correspond to cut-off points used for classifying tertiles or quintiles, or to group means, rather than a precise threshold. Intakes below this are not necessarily inadequate. 


\begin{tabular}{|c|c|c|c|c|c|c|}
\hline Study & Country & $\begin{array}{l}\text { Definition } \\
\text { of sugars }\end{array}$ & Diet method & Age group & Results & $\begin{array}{c}\text { Range of sugars } \\
\text { associated with } \\
\text { highest micronutrient } \\
\text { intakes* }\end{array}$ \\
\hline $\begin{array}{l}\text { Vanhapelto \& } \\
\text { Seppänen (1983) }\end{array}$ & Sweden & $\begin{array}{l}\text { Sugar } \\
\text { (unspecified) }\end{array}$ & Diet history & Adults & $\begin{array}{l}\text { Nutrient intakes were adequate in highest } \\
\text { and lowest deciles of sugar, among } \\
\text { both men and women. However, Fe } \\
\text { was low in both groups of women }\end{array}$ & None given \\
\hline $\begin{array}{l}\text { Linseisen } \\
\quad \text { et al. }(1998)^{24}\end{array}$ & Germany & Sucrose & 7Ddiary & All & $\begin{array}{l}\text { Sucrose energy was negatively associated } \\
\text { with intakes of micronutrients, except } \\
\mathrm{Ca} \text {, vitamin } \mathrm{E} \text {, vitamin } \mathrm{C} \text {, and dietary } \\
\text { fibre. Fewer individuals met } \\
\text { recommendations in the high sucrose } \\
\text { category under the condition of a } \\
\text { comparable energy intake }\end{array}$ & Moderate intake (10\%) \\
\hline $\begin{array}{l}\text { Bolton-Smith } \\
\qquad \text { et al. }(1995)^{25}\end{array}$ & UK & NMES & FFQ & Adults & $\begin{array}{l}\text { Both low and high extrinsic sugar intake } \\
\text { associated with poorer antioxidant } \\
\text { vitamin and fibre-containing diets. DRV } \\
\text { for sugars err on the cautious side }\end{array}$ & $\begin{array}{l}6.5-15.6 \% \text { (men) } \\
\quad \text { and } 4.8-11.6 \% \\
\text { (women) }\end{array}$ \\
\hline Gibson (1997) 26 & UK & NMES & 4WDR & $\begin{array}{l}\text { Pre-school } \\
\text { children }\end{array}$ & $\begin{array}{l}\text { The impact of nutrient dilution was small } \\
\text { below about } 20 \% \text { energy from NMES. } \\
\text { Intakes of most micronutrients (except } \\
\text { vitamin C) fell with increasing sugars } \\
\text { intake but were adequate in comparison } \\
\text { with DRV. Fe and Zn were low generally } \\
\text { and below the EAR in the highest quintile } \\
\text { ( }>24 \% \text { NMES) }\end{array}$ & $<20 \%$ \\
\hline Gibson $(2001)^{27}$ & UK & NMES & 4WDR & Older adults & $\begin{array}{l}\text { Intakes of micronutrients tended to be } \\
\text { highest at moderate levels of NMES } \\
\text { ( } 8-15 \% \text { energy). There was little evidence } \\
\text { that poorer nutrient status (biochemical) } \\
\text { was associated with higher levels of NMES }\end{array}$ & $8-15 \%$ \\
\hline Gibson $(1997)^{22} \dagger$ & UK & NMES & 7WDR & Adults & $\begin{array}{l}\text { Many nutrients showed a non-linear } \\
\text { relationship with sugars energy (added, } \\
\text { NMES, or total). Intakes fell in Q4 and Q5 } \\
\text { (>15\% added sugars or }>\text { about } 17 \% \\
\text { NMES) but were above RNI (except for Fe } \\
\text { and folate among women). NMES intakes } \\
\text { providing up to about } 17 \% \text { of food energy } \\
\text { did not compromise micronutrient intakes }\end{array}$ & $<17 \%$ NMES \\
\hline $\begin{array}{l}\text { Farris et al. } \\
\quad(1998)^{28}\end{array}$ & USA & Total & 24RCL & Children & $\begin{array}{l}\text { High consumers (top quartile, mean } 19 \% \text { ) had } \\
\text { lower intakes of } \mathrm{Fe}, \mathrm{Zn} \text { and vitamins } \mathrm{B}_{3} \text {, } \\
\mathrm{B}_{6} \text {, and } \mathrm{E} \text { but higher intakes of } \mathrm{Ca} \text { and } \\
\text { vitamin } \mathrm{D}\end{array}$ & None given \\
\hline $\begin{array}{l}\text { Naismith } \\
\quad \text { et al. }(1995)^{29}\end{array}$ & UK & Total & 7WDR & Children & $\begin{array}{l}\text { Intake of niacin fell (but exceeded RNI), while } \\
\text { vitamin } \mathrm{C} \text { and Ca rose }\end{array}$ & $<27 \%$ total sugars \\
\hline Gibson $(1993)^{30}$ & UK & Total & 14Ddiary & $\begin{array}{l}\text { Children, } \\
\text { youth }\end{array}$ & $\begin{array}{l}\text { Inconsistent trends were observed. } \\
\text { Vitamins } \mathrm{A}, \mathrm{C} \text { and thiamin were similar } \\
\text { across tertiles, } \mathrm{Ca} \text { and riboflavin increased, } \\
\text { Fe and other } \mathrm{B} \text { vitamins fell, although not } \\
\text { all differences were significant }\end{array}$ & None given \\
\hline Gibson $(1997)^{22} \dagger$ & UK & Total & 7WDR & Adults & $\begin{array}{l}\text { Low consumers of total sugars (Q1; } 11 \% \\
\text { energy) had lowest intakes of Ca, } \\
\text { vitamin C, riboflavin and folate. Energy } \\
\text { intakes also low in Q1 }\end{array}$ & $>11 \%$ total sugars \\
\hline
\end{tabular}

$7 \mathrm{Ddiary}=7 \mathrm{~d}$ dietary diary; NMES $=$ non-milk extrinsic sugars; DRV $=$ dietary reference value; $4 \mathrm{WDR}=4 \mathrm{~d}$ weighed dietary record; EAR $=$ estimated average requirement; $7 \mathrm{WDR}=7 \mathrm{~d}$ weighed dietary record; $\mathrm{Q} 1=$ first quintile; $\mathrm{Q} 4=$ fourth quintile; $\mathrm{Q} 5=$ fifth quintile; $\mathrm{RNI}=$ reference nutrient intake; $24 \mathrm{RCL}=24 \mathrm{~h}$ recall; $14 \mathrm{Ddiary}=14 \mathrm{~d}$ dietary diary.

* Ranges correspond to cut-off points used for classifying tertiles or quintiles, or to group means, rather than a precise threshold. Intakes below this are not necessarily inadequate.

† Gibson ${ }^{22}$ used three definitions (added, NMES, total sugars) 
Table 4. Observational studies of food and drinks containing sugars

\begin{tabular}{|c|c|c|c|c|c|c|}
\hline Study & Country & Definition & Diet method & Age group & Results & $\begin{array}{l}\text { Range of sugars } \\
\text { associated } \\
\text { with highest } \\
\text { micronutrient } \\
\text { intakes* }\end{array}$ \\
\hline Guenther $(1986)^{31}$ & USA & Soft drinks & $\begin{array}{l}\text { 24RCL and } \\
\text { 2Ddiary }\end{array}$ & Children, youth & $\begin{array}{l}\text { Weak negative partial correlations with intakes } \\
\text { of } \mathrm{Ca}(-0.11), \mathrm{Mg}(-0.06) \text {, riboflavin } \\
(-0.09) \text {, vitamin } \mathrm{A}(-0.08) \text { and vitamin } \mathrm{C}(-0.06)\end{array}$ & $\mathrm{N} / \mathrm{A}$ \\
\hline Harnack et al. (1999) ${ }^{32}$ & USA & Soft drinks & $2 \times 24 R C L$ & Children, youth & $\begin{array}{l}\text { High soft drink consumers }(>9 \mathrm{oz} / \mathrm{d} ; 255 \mathrm{~g} / \mathrm{d}) \\
\text { consumed less milk and fruit juice }\end{array}$ & $\mathrm{N} / \mathrm{A}$ \\
\hline Ballew et al. $(2000)^{33}$ & USA & Soft drinks & $24 \mathrm{RCL}$ & Children, youth & $\begin{array}{l}\text { Carbonated soda consumption was negatively } \\
\text { associated with achieving recommended } \\
\text { vitamin } \mathrm{A} \text { intake (all ages), Ca ( }<12 \text { years }) \\
\text { and } \mathrm{Mg}(6+\text { years })\end{array}$ & $\mathrm{N} / \mathrm{A}$ \\
\hline $\begin{array}{l}\text { Mrdjenovic \& } \\
\quad \text { Levitsky }(2003)^{34}\end{array}$ & USA & Soft drinks & Recall & Children & $\begin{array}{l}\text { Small study }(n 30) \text {. Sweetened drink } \\
\text { consumption }(>12 \mathrm{oz} / \mathrm{d} ; 340 \mathrm{~g} / \mathrm{d}) \text { displaced } \\
\text { milk from children's diets }(122-147 \mathrm{~g} \text { less } \\
\text { milk per d) (because caregivers served less milk) }\end{array}$ & $\mathrm{N} / \mathrm{A}$ \\
\hline Storey et al. (2004) & USA & Soft drinks & $24 \mathrm{RCL}$ & Children, youth & $\begin{array}{l}\text { Carbonated soft drink consumption among } \\
\text { adolescent girls is modest (mean } 12 \mathrm{oz} ; \\
340 \mathrm{~g} / \mathrm{d} \text { ) and does not appear to be linked } \\
\text { to decreased Ca intake }\end{array}$ & $\mathrm{N} / \mathrm{A}$ \\
\hline Marshall et al. (2005) ${ }^{36}$ & USA & Soft drinks & 3Ddiary & Young children & $\begin{array}{l}\text { Consumption of added sugar beverages was } \\
\text { inversely associated with intakes of } \mathrm{Ca} \text { and milk }\end{array}$ & $\mathrm{N} / \mathrm{A}$ \\
\hline Frary et al. (2004) & USA & $\begin{array}{l}\text { Sweet food } \\
\text { and drink }\end{array}$ & $2 \times 24 R C L$ & Children, youth & $\begin{array}{l}\text { Consumption of sweetened dairy foods and } \\
\text { presweetened cereals had a positive impact on diet } \\
\text { quality, whereas sugar-sweetened beverages, sugars, } \\
\text { sweets, and sweetened bakery products } \\
\text { had a negative impact }\end{array}$ & $\mathrm{N} / \mathrm{A}$ \\
\hline $\begin{array}{l}\text { Rodriguez-Artalejo } \\
\text { et al. }(2003)^{38}\end{array}$ & Spain & $\begin{array}{l}\text { Sweet food } \\
\text { and drink }\end{array}$ & FFQ & Children & $\begin{array}{l}\text { Consumption of sweetened soft drinks was } \\
\text { modest but associated with a lower } \\
\text { consumption of milk }(-88 \mathrm{ml}) \text { and } \mathrm{Ca} \\
(-175 \mathrm{mg} / \mathrm{d})\end{array}$ & $\mathrm{N} / \mathrm{A}$ \\
\hline Johnson $(2002)^{39}$ & USA & Flavoured milk & $24 \mathrm{RCL}$ & Children, youth & $\begin{array}{l}\text { Children who consumed flavoured milk had } \\
\text { higher total milk intakes and lower soft } \\
\text { drink and fruit drink intakes. Added sugars } \\
\text { in nutritious foods such as dairy products } \\
\text { may increase intakes of at-risk nutrients } \\
\text { such as Ca }\end{array}$ & $\mathrm{N} / \mathrm{A}$ \\
\hline
\end{tabular}

$24 \mathrm{RCL}=24 \mathrm{~h}$ recall; $2 \mathrm{Ddiary}=2 \mathrm{~d}$ dietary diary; $\mathrm{N} / \mathrm{A}=$ not applicable; 3Ddiary $=3 \mathrm{~d}$ dietary diary.

${ }^{*}$ Ranges correspond to cut-off points used for classifying tertiles or quintiles, or to group means, rather than a precise threshold. Intakes below this are not necessarily inadequate. 
However, in 2000 the Dietary Guidelines Advisory Committee concluded that it was not possible to make specific recommendations regarding a maximum amount of sugars intake without further examination of typical dietary patterns $^{43}$. The 2000 Dietary Guidelines Advisory Committee called for better definition of added and total sugars and more research to determine whether there are reasons to distinguish between the two. In 2002, new dietary reference intakes for macronutrients were issued by the Institute of Medicine following an extensive review of the international literature and reanalysis of data from the third National Health and Nutrition Examination Survey (NHANES III). The report ${ }^{44}$ concluded that added sugars intake should not exceed $25 \%$ of energy, based on reduced intakes of some micronutrients by certain groups (notably teenage girls) above this level, but also noted evidence for suboptimal intakes at very low levels $(0-5 \%$ of total energy from added sugars).

\section{Reviews}

Six reviews on this topic have been published since $1995^{45-50}$. All drew broadly similar conclusions, finding the evidence for micronutrient dilution to be inconsistent between nutrients and between age and sex groups. Where there was evidence for a negative impact of sugars on micronutrient intake, this was generally weak. The reviews also noted that some trends appeared non-linear, with suboptimal intakes at both very high and very low levels of sugars. They stressed the importance of considering dilution in the context of micronutrient requirements; for the general population with a sufficient energy intake, nutrient adequacy can be achieved across a wide range of dietary sugars. In attempting to quantify the optimal range, BoltonSmith suggested 5-12\% (extrinsic sugars or NMES) for women and $6-16 \%$ for men, the stricter range for women reflecting their lower energy intakes. For children, Ruxton et al. concluded that heterogeneity between nutrients made this difficult to determine precisely but suggested that the most micronutrient-dense diets were achieved by those consuming average amounts of added sugars (suggested as $14-20 \%)^{47}$. The most comprehensive and recent review, by Rennie \& Livingstone, found 'no clear evidence of micronutrient dilution or a threshold for a quantitative amount of added sugar intake ${ }^{50}$. However, they also highlighted methodological issues such as energy adjustment and misreporting that constrain or confound the evidence base. They suggested that future studies should attempt to quantify the magnitude of associations and also evaluate the role of particular foods, or food patterns, that may be leading to inadequate nutrient intakes. In a similar vein, Murphy \& Johnson concluded that in giving guidance to consumers, the focus should be on nutrient-dense dietary choices rather than on sugars concentration alone ${ }^{49}$. The primary data on which these reviews were based will be discussed individually.

\section{Interventions}

Only four intervention studies were identified that involved diets high in sugars or, more generally, refined or simple carbohydrates (Table 1). The earliest study by Heaton et al. was a cross-over trial comparing the effects of a diet high or low in refined carbohydrate for 6 weeks each in twenty-eight adults who either had gallstones or diabetes ${ }^{4}$. Intakes of most vitamins and minerals were significantly lower on the refined carbohydrate regimens (except $\mathrm{Ca}$, which was higher due to fortification of white bread). The diets were ad libitum and no restriction was placed on animal foods, but the subjects on the refined carbohydrate regimen were instructed to eat only white-flour products, to take sugar in drinks and on cereal, to eat confectionery and also limit their intake of fruit and vegetables and potatoes (i.e. displacement was built into the study by avoidance of wholegrain etc). Second, although adequacy was not commented on, nutrient intakes would not appear low, except perhaps for folate. In the study by Cline et al. ${ }^{5}$ on military recruits undergoing a desert field exercise, the group given carbohydrate drink ad libitum in addition to rations had higher energy intakes but significantly lower intakes of protein, $\mathrm{Ca}, \mathrm{Mg}$ and $\mathrm{Zn}$, compared with those receiving a non-energy placebo drink. Although intakes of minerals and some B vitamins fell short of the RDA, biochemical data remained within reference ranges in both groups. In contrast with this study, an 8-week parallel-design weight-reduction study among sixty-eight men ${ }^{6}$ found no evidence of micronutrient dilution that could be attributed to sucrose content. However, in this study the two contrasting regimens were both relatively low in sugar (5 v. $10 \%$ sucrose). The fourth study using forty-six overweight participants in the Danish cohort of the CARMEN study ${ }^{51}$ investigated the impact of two low-fat diets, one high in 'simple carbohydrates', the other high in complex carbohydrates over 6 months $^{7}$. The high simple carbohydrates group (26\% energy simple carbohydrates) had lower intakes of $\mathrm{Zn}$ and vitamin $\mathrm{B}_{12}$, compared with the complex carbohydrates group or habitual diet group, but this may be clinically unimportant given that intakes were above recommended levels. There were no other diet differences between the groups and the authors concluded that the micronutrient contents of the diets were similar. These interventions therefore appear to suggest a minor impact of high-sugar diets on some nutrients. However, the evidence is far from conclusive with regard to strength of association, causality, or importance for nutritional status.

\section{Epidemiological studies relating to dietary sugars and micronutrient dilution}

Most of the evidence in this area has been derived from observational studies, many of which are cross-sectional national or regional studies that are broadly representative of the population. Older studies tended to define sugars as total sugars, but since the late 1990s the majority have differentiated added sugars or NMES. The effect of using different definitions in the same dataset has also been assessed $^{22,25}$. There is also inconsistency between studies in the assessment of micronutrient adequacy. This arises partly from different recommendations in various countries but also from different reference criteria (for example, reference nutrient intake, two-thirds of reference nutrient intake, estimated average requirement, lower reference nutrient 
intake) and different statistical approaches (mean $v$. prevalence) (Tables 2 and 3).

\section{American studies using national datasets}

Large American datasets have provided the basis for many observational studies, in particular the Continuing Survey of Food Intakes by Individuals (CSFII), its predecessor the 1977-8 Nationwide Food Consumption Survey (NCFS) and NHANES III.

In an early study using the $1977-8$ NFCS, Lewis et al. ${ }^{15}$ found that high consumers of added sugars (above 75th percentile or 16-25\% energy) took in lower percentages of the RDA for eleven vitamins and minerals than did their counterparts consuming $15 \%$ added sugars or less (moderate consumers). There was considerable variation between nutrients and age groups but the median dilution was 13 (range 1-29) \%. Ca intakes among 4-10 year olds were $18 \%$ lower in high $v$. moderate consumers (95 v. $113 \%$ RDA) and $16 \%$ lower for 11-18 year olds (68 v. $84 \%$ RDA).

Farris et al. investigated nutrient intake in relation to total sugars intake among 10 year olds in the Bogalusa study, and reported inverse trends with amounts of $\mathrm{Fe}, \mathrm{Zn}$, niacin, and vitamins $\mathrm{B}_{6}$ and $\mathrm{E}$, but positive trends with $\mathrm{Ca}$ and vitamin $\mathrm{D}^{28}$. This was consistent with the lower intakes of meat and higher intakes of milk among high consumers. The authors concluded that intakes of most vitamins and minerals were adequate among high sugar consumers (mean 19\% energy from total sugars). However, 24 and $21 \%$ of low consumers (mean $9 \%$ energy from sugars) and 44 and $34 \%$ of high consumers had intakes of Fe and $\mathrm{Zn}$, respectively, that were below two-thirds of the RDA.

Using $24 \mathrm{~h}$ recall data on over 14000 individuals from CSFII 1994-6, Bowman ${ }^{10}$ divided respondents into three groups based on percentage energy from added sugars (\%EAS). These corresponded to $<10 \%, 10-18 \%$ and $>18 \%$ EAS. High consumers $(>18 \%$ EAS; mean $26.7 \%$ EAS) had lowest intakes of all micronutrients, although means still exceeded two-thirds of the RDA. Low consumers $(<10 \%$ added sugars) did not have significantly higher nutrient intakes than average consumers (10-18\% added sugars). Data on preschool children from the same survey were recently reported as showing that $\mathrm{Ca}$ intake was insufficient in large proportions of children consuming $16 \%$ energy or more from added sugars ${ }^{14}$, intakes of $>21 \%$ being problematic. By contrast, using the same database but employing a multiple regression method incorporating components of energy ( $\mathrm{kJ}$ from sugars $v$. $\mathrm{kJ}$ from other foods), Forshee \& Storey concluded that the associations between added sugars and micronutrients varied with age group and ranged from no association to a statistically significant association that was positive or negative. They commented that the effects of added sugars were so small as likely to be of no clinical importance ${ }^{12}$. In a study looking at dietary quality using the healthy eating index (rather than micronutrient intakes) in CSFII data, Britten et al. concluded that the association was complex and depended on energy intake. Most high consumers of added sugars had high energy intakes and their intake of food groups (other than fruit) was not consistently affected. Others compensated for the additional energy from sugars by reducing intake of other foods (fruit, vegetable, milk and grains) ${ }^{11}$.

In the course of gathering evidence for dietary recommendations, the Institute of Medicine report ${ }^{44}$ examined the median intakes of micronutrients at every 5 th percentile of added sugars intake for each age and sex group in NHANES III. Reduced intakes of $\mathrm{Ca}$, vitamin $\mathrm{A}$, $\mathrm{Fe}$ and $\mathrm{Zn}$ were observed in some groups both at low levels of added sugars $(<5 \%)$ and at high levels above $25 \%$ of energy. High sugar intakes were more common among adolescents than adults ${ }^{44}$, although prevalence cannot be estimated very accurately from the $24 \mathrm{~h}$ data in this survey 52,53

There was evidence of a subtle decline in energy intakes at both extremes of the spectrum $(<5 \%$ EAS and $>30 \% \mathrm{EAS})^{44}$, similar to the pattern observed with $\mathrm{Ca}$ intakes. Forshee \& Storey have argued that the association observed between \%EAS and intake of micronutrients may be spurious and caused by the relationships between total energy and micronutrients ${ }^{3}$. They have criticised the use of percentage energy from sugars as fundamentally flawed, on the grounds that it does not properly control for energy but presupposes a 1:1 displacement. Using an alternative approach (energy partitioning) they concluded that energy (MJ) from added sugars had little or no association with diet quality (when energy from other sources is kept constant), whereas energy from other sources had a much stronger and more consistent association when energy from sugars is kept constant ${ }^{3}$. The approach of Forshee et al. has in turn been criticised as not adequately adjusting for total energy ${ }^{54}$. This is a conceptual controversy as much as a statistical one and the two approaches may be irreconcilable ${ }^{55}$. Given the discrepancy in results and the implications for policy, this deserves further scrutiny and debate by nutritionists, epidemiologists and biostatisticians.

\section{Studies in Europe and other countries}

We examined observational studies from Britain $^{16,22,25-27,29,30}$, Germany ${ }^{17-19,24}$, Sweden ${ }^{23}$, Norway ${ }^{20}$, Spain $^{38}$, Ireland ${ }^{21}$, Australia ${ }^{9}$ and South Africa ${ }^{8,13}$. A few were based on small numbers of individuals, limiting the power to detect associations ${ }^{21,29}$. The results of studies on children and adults are discussed separately below, although findings were broadly similar.

Children. A review by Rugg-Gunn et al., the earliest study of children, set the scene for the debate on 'empty calories' and micronutrient dilution ${ }^{16}$. This small survey of adolescents aged 11-14 years found mostly low-level and non-significant correlations for most nutrients with added sugars $(\mathrm{g} / \mathrm{MJ})$, except for vitamin $\mathrm{D}(r-0.25 ; P<0.001)$, where there was a significant difference in intake between the highest (19\% sugars) and lowest decile (10\% sugars) (vitamin D 1.4 v. $2.4 \mu \mathrm{g} / \mathrm{d}$ ). Subsequently, Gibson ${ }^{30}$, from a nationwide sample of 2705 British schoolchildren, reported trends with micronutrient intake that were inconsistent: $\mathrm{Ca}$ and riboflavin increased with (total) sugars intake, while $\mathrm{Fe}$ fell and vitamins $\mathrm{A}$ and $\mathrm{C}$ and thiamin were similar ${ }^{30}$. Among pre-school children in the British National Diet and Nutrition Survey, we also found inverse associations 
between NMES (as a percentage of energy intake) and most micronutrients, but a positive association with vitamin $\mathrm{C}^{26}$. Lower intakes of meat, milk, fruit and vegetables and higher intakes of fruit juice and drinks largely explained these associations. Mean intakes of Fe, $\mathrm{Zn}$ and vitamin $\mathrm{D}$ in these young children were low at all levels of NMES; other nutrients were above reference levels. It was concluded that the impact of sugars was small below about $20 \%$ NMES and of most significance for those with intakes $>24 \%$ NMES. A Norwegian study among children aged 4, 9 and 13 years found similar inverse associations of added sugars (percentage of energy intake) with most nutrients, except for vitamin $\mathrm{C}$ and vitamin $\mathrm{E}$ in some groups ${ }^{20}$ while intakes of fruit and vegetables were 30-40\% lower among high sugar groups (above 18-22\% added sugars), compared with low sugar groups (below 11-13\% sugars). In Germany, a series of papers from the Dortmund Nutritional and Anthropometric Longitudinally Designed (DONALD) study reported weak inverse associations between added sugars in the diet and micronutrient intakes ${ }^{19}$. The authors proposed that the positive impact of energy intake and fortification was larger than the negative impact of sugars ${ }^{17}$. Since nutrient intakes were generally adequate (or in the case of folate, inadequate) regardless of sugars intake, the authors did not consider that a quantitative limit on sugars intake was justified on ground of micronutrient dilution. However, on grounds of dietary quality, they suggested a range of 6-10\% energy from added sugars ${ }^{18}$.

Adults. In a study of 2800 Australian men and women, Baghurst et al. ${ }^{9}$ found that many (but not all) nutrients declined slightly with increasing added sugars intake but were generally regarded as adequate even in the top decile ( $>18 \%$ added sugars). An early Swedish national study by Vanhapelto et al. ${ }^{23}$ also found that intakes of minerals and vitamins were generally adequate in both the highest and lowest sugar consumers (deciles). However, Fe intakes among women were universally low, as is well established in many populations.

A number of studies have suggested that some associations with nutrients may be curvilinear, with nutrient intakes optimal at average levels of sugar intake. In a large study of over 11000 adults in Scotland, diets either very high or low in extrinsic sugars were associated with the lowest intake of antioxidant vitamins, with optimal intakes in the range of 6-16\% for men, and 5-12\% for women ${ }^{25}$. Similar findings have been reported using data from British surveys (National Diet and Nutrition Survey series), where there was little evidence of compromised micronutrient intakes up to about $17 \%$ energy from NMES (or about $15 \%$ added sugars) among adults ${ }^{22}$, and highest intakes in the range from $8-15 \%$ energy from NMES in older individuals $^{27}$. It is important to establish whether the low nutrient intakes seen with low-sugar diets are real (for example, an indication of high fat intake and poor diet quality, or low palatability and low energy intake) $)^{56,57}$ or artifact (for example, due to unreliable records).

Two studies from South Africa by Charlton et al. ${ }^{8,13}$ constituted the only evidence on micronutrient dilution from less developed countries. In 1998 they found inverse associations between the intake of most micronutrients and percentage energy from added sugars in a free-living elderly population ${ }^{8}$. More recently they found evidence of poorer nutrient intakes and status among women, but not men. This was in the context of lower energy intakes (the third tertile were only $86 \%$ of those in the second tertile) and evidence of generally inadequate intakes and a poor nutritional status across all tertiles of added sugars intake. From a regression analysis they found that added sugars (g/d) explained at most $2 \%$ of the variance in intake of different nutrients whereas energy explained between 20 and $64 \%{ }^{13}$. Similarly in the National Diet and Nutrition Survey of older individuals, we found that NMES (percentage of energy intake) explained between 2 and $4 \%$ of the variance in intakes of 'at-risk' nutrients ( $\mathrm{Fe}, \mathrm{Ca}$, riboflavin and folate), while energy explained between 20 and $40 \%{ }^{27}$. In Forshee's regression analysis of CSFII data, correlations between $\%$ EAS and Ca ranged between -0.09 and -0.29 ( 1 to $8 \%$ of the variance explained), whereas correlations between energy and Ca were 0.56 to 0.66 (31-44\% of the variance explained). These comparisons suggest that the independent influence of added sugars on micronutrient intake is relatively weak.

\section{Studies relating to soft drinks and other sweetened beverages}

Consumption of sweetened soft drinks is particularly high among American children and adolescents, and several studies have examined the putative displacement of micronutrients by soft drinks. Using $24 \mathrm{~h}$ recall data from the 1977-8 Nationwide Food Consumption Survey, Guenther noted weak negative correlations ( -0.06 to -0.11 ) among teenagers between soft drinks and $\mathrm{Ca}, \mathrm{Mg}$, vitamin $\mathrm{A}$, riboflavin and vitamin $\mathrm{C}$ and also with milk (Table 4) ${ }^{31}$. Subsequently, two studies based on the 1994 US CSFII data found high consumption of sweetened soft drinks among children and adolescents to be associated with lower intake of milk and fruit juice and their associated nutrients $^{32,33}$. In the study by Harnack et al. intakes of $\mathrm{Ca}$, riboflavin, vitamin $\mathrm{A}$, folate and vitamin $\mathrm{C}$ were inversely associated with soft drink consumption but this was particularly evident among those consuming $>26 \mathrm{oz} / \mathrm{d}$ ( $>737 \mathrm{~g} / \mathrm{d}$ ), who had reductions of $20-45 \%$ compared with low or non-consumers ${ }^{32}$. Using $24 \mathrm{~h}$ recall data from children aged 2-17 years in CSFII 1994-6, Ballew et al. found that (carbonated) soft drinks were negatively associated with vitamin $\mathrm{A}$ at all ages, $\mathrm{Mg}$ intakes (among 6 year olds and over) and Ca (among under 12 year olds) ${ }^{33}$. By contrast, in the same survey Storey et al. found that intake of carbonated soft drinks was more modest among adolescent girls (age 14-18 years) and did not appear to be linked to decreased $\mathrm{Ca}$ intake ${ }^{35}$. Frary et al. found that consumption of pre-sweetened beverages, sweets and baked products had a negative impact on nutrients intake whereas sweetened dairy foods and cereals had a positive impact. ${ }^{38}$ Among 645 pre-school children in Iowa, USA, Marshall et al. recently reported that sweetened beverages were significantly inversely associated with mean nutrient adequacy ratios $(r-0.02$ to -0.25$)$, although associations with vitamin $\mathrm{A}$ and $\mathrm{Cu}$ were positive $(r+0 \cdot 19,+0 \cdot 21)^{36}$. (A nutrient adequacy ratio is the ratio of an individual's 
mean intake relative to their age- or sex-specific RDA.) Another study of only thirty children that reported displacement of milk by sweetened drinks ${ }^{34}$ has been criticised $^{58,59}$. Surveys from other countries have not found such strong associations with soft drinks as in the USA, possibly because consumption levels are lower. For example, among Spanish children aged 6-7 years, sweetened soft drinks were inversely associated with milk consumption and $\mathrm{Ca}$ intake, but this was partly offset by increased consumption of other dairy products, so that $\mathrm{Ca}$ remained above recommended levels ${ }^{38}$. In contrast to the American studies, there was a positive (but non-significant) association between soft drinks and fruit juice consumption, suggesting that inverse associations with nutrient-rich foods are not inevitable (Table 4).

\section{Conclusions}

The publications reviewed provide some evidence that diets containing a high proportion of added sugars are slightly lower in micronutrients than diets containing a moderate proportion of added sugars. However, results were not necessarily linear or consistent across nutrients, populations and age groups and quantification is hampered by different cut-off criteria in each study. Most of the evidence reviewed comes from cross-sectional observational studies. These provide good evidence of the range of dietary practices in real life but they cannot predict the impact of alterations in added sugars intake. Prospective and intervention studies are required to study these aspects, but these must have sufficient statistical power and use good dietary methodologies.

Studies based on percentage energy from total sugars have tended to show positive associations with vitamin $\mathrm{C}$ and sometimes with $\mathrm{Ca}^{30}$, due to inclusion of sugars in fruit and milk. Studies defining sugars as NMES (which includes sugars in fruit juice and $50 \%$ of the sugars in processed and dried fruit) have sometimes shown positive associations with vitamin $\mathrm{C}$ for the same reason. Associations of percentage energy from added sugars with vitamin $\mathrm{C}$ have variously been shown to be negative, positive or neutral. The majority of studies on soft drink consumption indicate that high intakes are negatively associated with some nutrients, especially those found in milk and fruit juice. The form in which sugars are consumed appears an important modifier of the impact of dilution. Soft drinks, sugar and sweets are more likely to have a negative impact on diet quality whereas dairy foods, milk drinks and pre-sweetened cereals may have a positive impact ${ }^{37,45}$.

Optimal intakes of sugars are difficult to quantify because associations vary between nutrients and depend on food choice and composition. It is established that energy intake is the prime predictor of micronutrient adequacy and a modifier of the associations with sugars ${ }^{11,55,56}$. What is debated is the appropriate adjustment for energy ${ }^{2}$. Epidemiologists routinely use percentage energy (sometimes with additional adjustment for energy differences) to quantify the independent association of sugar or fat in diet/ heath relationships and virtually all the studies considered in the present review used this method. Overall, the studies suggest micronutrient intakes are optimal at moderate levels of sugars in the diet, provided energy needs are met. Very high intakes of added sugars or NMES in excess of $20 \%$ of energy are associated with lower intakes of several micronutrients. In some studies, very low intakes of all types of sugars (i.e. diets containing $<5 \%$ energy from sugars) are also associated with poor nutrient intakes. More data are required to investigate whether this is associated with dieting, under-reporting, illness, unbalanced diets (for example, very high-fat diets) or other confounding factors. More studies are also needed from developing countries, where energy intakes, dietary variety and fortification may be more limited.

Ultimately the nutritional significance of dilution depends on whether micronutrient intakes are adequate with respect to requirements, or since these are largely unknown, compared with group recommended levels or cut-off points. Micronutrient intakes were commonly described as 'adequate' in the studies reviewed but the criteria varied. Comparison of group means with the reference nutrient intake (or two-thirds of the reference nutrient intake or estimated average requirement) is a common criterion against which adequacy is judged but it cannot assess the likely prevalence of inadequacy. The estimated average requirement cut-off point method is now established as the best measure of this ${ }^{60}$ but estimates can be inflated by under-reporting and use of $24 \mathrm{~h}$ dietary data without correction for within-individual variation ${ }^{53,61}$. Conversely, use of the lower reference nutrient intake as a cut-off underestimates the true prevalence of inadequacy in populations ${ }^{62}$. Given the varied criteria, generalisations such as 'sugars compromise nutrient intakes' (or conversely 'micronutrient intakes are adequate irrespective of sugars intake') are unhelpful in resolving current public health issues. The available evidence does not allow for firm conclusions on an optimal level of added sugars intake on the basis of micronutrient adequacy; indeed, there is some doubt as to whether some of the associations seen between sugars intake and micronutrients reliably reflect meaningful biological relationships. A better understanding of valid approaches to energy adjustment, misreporting and assessment of micronutrient adequacy is therefore crucial to further progress in this area.

\section{Acknowledgements}

The World Sugar Research Organisation provided funding towards the present review. The author is an independent consultant in nutrition science, working with a variety of commercial and non-commercial organisations.

\section{References}

1 Thomson ResearchSoft (2004) EndNote. http://www.endnote. com/

2 Mackerras D (1996) Energy adjustment: the concepts underlying the debate. J Clin Epidemiol 49, 957-962.

3 Forshee RA \& Storey ML (2004) Controversy and statistical issues in the use of nutrient densities in assessing diet quality. J Nutr 134, 2733-2737.

4 Heaton KW, Emmett PM, Henry CL, Thornton JR, Manhire A \& Hartog M (1983) Not just fibre - the nutritional 
consequences of refined carbohydrate foods. Hum Nutr Clin Nutr 37, 31-35.

5 Cline AD, Tharion WJ, Tulley RT, Hotson N \& Lieberman HR (2000) Influence of a carbohydrate drink on nutritional status, body composition and mood during desert training. Aviat Space Environ Med 71, 37-44.

6 West JA \& de Looy AE (2001) Weight loss in overweight subjects following low-sucrose or sucrose-containing diets. Int J Obes Relat Metab Disord 25, 1122-1128.

7 Vasilaras TH, Astrup A \& Raben A (2004) Micronutrient intake in overweight subjects is not deficient on an ad libitum fat-reduced, high-simple carbohydrate diet. Eur J Clin Nutr 58, 326-336.

8 Charlton KE, Wolmarans P \& Lombard CJ (1998) Evidence of nutrient dilution with a high sugar intake in older South Africans. J Hum Nutr Diet 11, 331-343.

9 Baghurst K, Baghurst P \& Record S (1992) Demographic and nutritional profiles of people consuming varying levels of sugars. Nutr Res 12, 1455-1465.

10 Bowman S (1999) Diets of individuals based on energy intakes from added sugars. Fam Econ Nutr Rev 12, 31-38.

11 Britten P, Basiotis PP, Davis CA \& Anand R (2000) Is intake of added sugars associated with diet quality? In Insight 21 [USDA Center for Nutrition Policy and Promotion, editor]. Washington, DC: USDA.

12 Forshee RA \& Storey ML (2001) The role of added sugars in the diet quality of children and adolescents. J Am Coll Nutr 20, 32-43.

13 Charlton KE, Kolbe-Alexander TL \& Nel JH (2005) Micronutrient dilution associated with added sugar intake in elderly black South African women. Eur J Clin Nutr 59, 1030-1042.

14 Kranz S, Smiciklas-Wright H, Siega-Riz AM \& Mitchell D (2005) Adverse effect of high added sugar consumption on dietary intake in American preschoolers. J Pediatr 146, $105-111$.

15 Lewis CJ, Park YK, Dexter PB \& Yetley EA (1992) Nutrient intakes and body weights of individuals consuming high and moderate levels of added sugars. J Am Diet Assoc 92, $708-713$.

16 Rugg-Gunn AJ, Hackett AF, Jenkins GN \& Appleton DR (1991) Empty calories? Nutrient intake in relation to sugar intake in English adolescents. J Hum Nutr Diet 4, 101-111.

17 Alexy U, Sichert-Hellert W \& Kersting M (2002) Fortification masks nutrient dilution due to added sugars in the diet of children and adolescents. J Nutr 132, 2785-2791.

18 Alexy U, Kersting M \& Schultze-Pawlitschko V (2003) Two approaches to derive a proposal for added sugars intake for German children and adolescents. Public Health Nutr 6, 697-702.

19 Alexy U, Sichert-Hellert W \& Kersting M (2003) Associations between intake of added sugars and intakes of nutrients and food groups in the diets of German children and adolescents. Br J Nutr 90, 441-447.

20 Øverby NC, Lillegaard IT, Johansson L \& Andersen LF (2004) High intake of added sugar among Norwegian children and adolescents. Public Health Nutr 7, 285-293.

21 Flynn MA, Suqrue DD, Codd MB \& Gibney MJ (1996) Women's dietary fat and sugar intakes: implications for food based guidelines. Eur J Clin Nutr 50, 713-719.

22 Gibson SA (1997) Do diets high in sugars compromise micronutrient intakes? Micronutrient intakes in the Dietary and Nutritional Survey of British Adults according to dietary concentration of 'added', 'non-milk extrinsic' or 'total' sugars. J Hum Nutr Diet 10, 125-133.
23 Vanhapelto AT \& Seppänen OR (1983) Nutrient intakes of persons with low or high consumption of sugar. Näringsforskning 3, 82-85.

24 Linseisen J, Gedrich K, Karg G \& Wolfram G (1998) Sucrose intake in Germany. Z Ernahrungswiss 37, 303-314.

25 Bolton-Smith C \& Woodward M (1995) Antioxidant vitamin adequacy in relation to consumption of sugars. Eur J Clin Nutr 49, 124-133.

26 Gibson SA (1997) Non-milk extrinsic sugars in the diets of pre-school children: association with intakes of micronutrients, energy, fat and NSP. Br J Nutr 78, 367-378.

27 Gibson S (2001) Dietary sugars and micronutrient dilution in normal adults aged 65 years and over. Public Health Nutr 4, $1235-1244$.

28 Farris RP, Nicklas TA, Myers L \& Berenson GS (1998) Nutrient intake and food group consumption of 10-year-olds by sugar intake level: the Bogalusa Heart Study. J Am Coll Nutr 17, 579-585.

29 Naismith D, Nelson M, Burley V \& Gatenby S (1995) Does a high-sugar diet promote overweight in children and lead to nutrient deficiencies? J Hum Nutr Diet 8, 249-254.

30 Gibson S (1993) Consumption and sources of sugars in the diets of British schoolchildren: are high-sugar diets nutritionally inferior? J Hum Nutr Diet 6, 355-371.

31 Guenther PM (1986) Beverages in the diets of American teenagers. J Am Diet Assoc 86, 493-499.

32 Harnack L, Stang J \& Story M (1999) Soft drink consumption among US children and adolescents: nutritional consequences. J Am Diet Assoc 99, 436-441.

33 Ballew C, Kuester S \& Gillespie C (2000) Beverage choices affect adequacy of children's nutrient intakes. Arch Pediatr Adolesc Med 154, 1148-1152.

34 Mrdjenovic G \& Levitsky D (2003) Nutritional and energetic consequences of sweetened drink consumption in 6- to 13-year-old children. J Pediatr 142, 604-610.

35 Storey ML, Forshee RA \& Anderson PA (2004) Associations of adequate intake of calcium with diet, beverage consumption, and demographic characteristics among children and adolescents. J Am Coll Nutr 23, 18-33.

36 Marshall TA, Eichenberger Gilmore JM, Broffitt MS, Stumbo PJ \& Levy SM (2005) Diet quality in young children is influenced by beverage consumption. J Am Coll Nutr 24, $65-75$.

37 Frary CD, Johnson RK \& Wang MQ (2004) Children and adolescents' choices of foods and beverages high in added sugars are associated with intakes of key nutrients and food groups. J Adolesc Health 34, 56-63.

38 Rodríguez-Artalejo F, García EL, Gorgojo L, Garcés C, Royo MA, Martín Moreno JM, Benavente M, Macías A \& De Oya M; Investigators of the Four Provinces Study (2003) Consumption of bakery products, sweetened soft drinks and yogurt among children aged 6-7 years: association with nutrient intake and overall diet quality. $B r J$ Nutr 89, 419-429.

39 Johnson RK, Frary C \& Wang MQ (2002) The nutritional consequences of flavored-milk consumption by school-aged children and adolescents in the United States. J Am Diet Assoc 102, 853-856.

40 Department of Health Committee on Medical Aspects of Food Policy (1989) Dietary sugars and human disease. In Report of the Panel on Dietary Sugars. London: H.M. Stationery Office.

41 World Health Organization and Food and Agriculture Organization (2003) Diet, Nutrition and the Prevention of Chronic Diseases. WHO Techical Report Series no. 916. Geneva: WHO. 
42 Department of Health (1991) Dietary Reference Values for Food Energy and Nutrients for the United Kingdom. London: H.M. Stationery Office.

43 Dietary Guidelines Advisory Committee (2000) Report of the Dietary Guidelines Advisory Committee on the Dietary Guidelines for Americans. Washington, DC: Departments of Health and Human Services and Agriculture.

44 Institute of Medicine (2002). Dietary Reference Intakes for Energy, Carbohydrate, Fat, Fibre, Fatty Acids, Cholesterol, Protein and Amino Acids. Washington, DC: Food and Nutrition Board.

45 Gibney M, Sigman-Grant M, Stanton JL Jr \& Keast DR (1995) Consumption of sugars. Am J Clin Nutr 62, Suppl. 1, 178S-194S.

46 Bolton-Smith C (1996) Intake of sugars in relation to fatness and micronutrient adequacy. Int J Obes Relat Metab Disord 20, Suppl. 2, S31-S33.

47 Ruxton CH, Garceau FJ \& Cottrell RC (1999) Guidelines for sugar consumption in Europe: is a quantitative approach justified? Eur J Clin Nutr 53, 503-513.

48 Ruxton $\mathrm{CH}$ (2003) Dietary guidelines for sugar: the need for evidence. Br J Nutr 90, 245-247.

49 Murphy SP \& Johnson RK (2003) The scientific basis of recent US guidance on sugars intake. Am J Clin Nutr 78, $827 \mathrm{~S}-833 \mathrm{~S}$.

50 Rennie KL \& Livingstone MB (2007) Associations between dietary added sugar intake and micronutrient intake: a systematic review. Br J Nutr 97, 832-841.

51 Saris WHM, Astrup A, Prentice AM, et al. (2000) Randomized controlled trial of changes in dietary carbohydrate/fat ratio and simple vs complex carbohydrates on body weight and blood lipids: the CARMEN study. The
Carbohydrate Ratio Management in European National diets. Int J Obes Relat Metab Disord 24, 1310-1318.

52 Institute of Medicine Food and Nutrition Board (2000) Dietary Reference Intakes: Applications in Dietary Assessment. Washington, DC: National Academies Press.

53 Kaplan RJ (2004) Proportion of the US population whose intakes of added sugars exceed the suggested maximum in the dietary reference intakes. Am J Clin Nutr 80, 524-525.

54 Barr SI \& Johnson RK (2005) Effect of added sugars on dietary quality. J Nutr 135, 1336-1337.

55 Forshee RA \& Storey ML (2005) Reply to Barr and Johnson. J Nutr 135, 1337.

56 Emmett P, Rogers I \& Symes C (2000) Food and nutrient intakes of a population sample of 3-year-old children in the South West of England in 1996. Public Health Nutr 5, 55-64.

57 Kant AK \& Schatzkin A (1994) Consumption of energydense, nutrient-poor foods by the US population: effect on nutrient profiles. J Am Coll Nutr 13, 285-291.

58 Sutherland LA (2004) Soft drinks and obesity. J Pediatr 144, 554.

59 Allport JH (2004) Soft drinks and obesity. J Pediatr 144, $554-557$.

60 Institute of Medicine Food and Nutrition Board (2003) Dietary Reference Intakes: Applications in Dietary Planning. Washington, DC: National Academies Press.

61 Mackerras D \& Rutishauser I (2005) 24 Hour national dietary survey data: how do we interpret them most effectively? Public Health Nutr 8, 657-665.

62 Hannon EM, Kiely M, Harrington KE, Robson PJ, Strain JJ \& Flynn A (2001) The North/South Ireland Food Consumption Survey: mineral intakes in 18-64-year-old adults. Public Health Nutr 4, 1081-1088. 